\title{
La localización espacial de los atractivos turísticos de un área metropolitana: diferencias entre material turístico institucional, guías turísticas y contenidos generados por los usuarios*
}

\author{
Daniel Paül i Agustí \\ Universitat de Lleida. Departament de Geografia i Sociologia \\ dpaul@geosoc.udl.cat
}

Recibido: junio de 2017

Aceptado: junio de 2018

Publicado: marzo de 2019

\section{Resumen}

El estudio se centra en las diferencias existentes en la distribución de los atractivos turísticos en función de tres fuentes: el material turístico institucional, las guías turísticas y los contenidos generados por los usuarios (imágenes de la red Instagram). Para ello se realiza una aproximación basada en el análisis espacial aplicada al área metropolitana de Montevideo (Uruguay). Los resultados indican que solo existe una coincidencia parcial entre la localización de las imágenes creadas por los usuarios y los atractivos promocionados por las instituciones y las guías turísticas. En términos generales, los usuarios tienden a fotografiar espacios alejados de los tradicionalmente promocionados. Este hecho apunta a una presencia mayor de los visitantes en el conjunto del área metropolitana. En consecuencia, podemos afirmar que la ciudad turística es más extensa que la tradicionalmente promocionada. Una situación que tiene repercusiones potenciales en aspectos como la identificación de nuevos atractivos, su gestión o la correcta valoración de los efectos que causa el turismo en el espacio urbano.

Palabras clave: distribución espacial; material turístico institucional; guías turísticas; redes sociales (Instagram); atractivos turísticos

* El trabajo se integra dentro del proyecto financiado por el Plan Nacional La gestión espacial de la conflictividad social (CSO2015-64643-R) y en el Grup de Recerca Consolidat "Territori i Societat", de la Generalitat de Catalunya (2014 SGR 973). El desplazamiento a Uruguay fue posible gracias a las Becas Iberoamérica. Santander Investigación 2016. Se agradece la colaboración de la profesora Rossana Campodónico, de la Universidad de la República (Uruguay). 
Resum. La localització espacial dels atractius turistics d'una àrea metropolitana: diferències entre material turistic institucional, guies turistiques i continguts generats pels usuaris

L'estudi es focalitza en les diferències existents en la distribució dels atractius turístics en funció de tres fonts: el material turístic institucional, les guies turístiques i els continguts generats pels usuaris (imatges de la xarxa Instagram). Per analitzar aquesta qüestió es realitza una aproximació basada en l'anàlisi espacial aplicada a l'àrea metropolitana de Montevideo (Uruguai). Els resultats indiquen que únicament existeix una coincidència parcial entre la localització de les imatges creades pels usuaris i els atractius promocionats per les institucions i les guies turístiques. En termes generals, els usuaris tendeixen a fotografiar espais allunyats dels tradicionalment promocionats. Aquest fet apunta a una presència més elevada de visitants en el conjunt de l'àrea metropolitana. En conseqüència, podem afirmar que la ciutat turística és més extensa que la tradicionalment promocionada. Una situació que té repercussions potencials en aspectes com ara la identificació de nous atractius, la seva gestió o la correcta valoració dels efectes que causa el turisme en l'espai urbà.

Paraules clau: distribució espacial; material turístic institucional; guies turístiques; xarxes socials (Instagram); atractius turístics

Résumé. La localisation spatiale des attraits touristiques d'une aire métropolitaine : différences entre le matériel promotionnel d'institutions, les guides touristiques et les contenus créés par les utilisateurs

L'étude porte sur les différences des attraits touristiques selon trois sources : des brochures touristiques, des guides touristiques et des contenus créés par les utilisateurs (images du réseau Instagram). Pour ce faire, une approche basée sur l'analyse spatiale a été réalisée dans la zone métropolitaine de Montevideo (Uruguay). Les résultats indiquent qu'il n'existe qu'une correspondance partielle entre l'emplacement des images créées par les utilisateurs et les attractions promues par les institutions et les guides touristiques. D'une manière générale, les utilisateurs ont tendance à photographier des espaces différents de ce qui font traditionnellement l'objet de promotion. Cela montre une plus grande présence de visiteurs dans l'ensemble de la région métropolitaine. Par conséquent, on peut signaler que la ville touristique est plus étendue que la promotion traditionnelle. Cette situation a des effets potentiels sur des aspects tels que l'identification de nouvelles attractions, leur gestion ou une correcte évaluation de l'impact du tourisme dans l'espace urbain.

Mots-clés: distribution spatiale; brochures touristiques institutionnelles; guides touristiques; réseaux sociaux (Instagram); lieux touristiques

\section{Abstract. The territorial distribution of tourist attractions in a metropolitan area: Differences between institutional tourism materials, travel guides and user-generated images}

This study analyses the extent of an overlap in the territorial distribution and attractiveness of tourist sights as depicted in three different media: institutional tourism materials, travel guides and user-generated content (images shared on the Instagram social network). To do so, a mixed-methods approach involving statistical and spatial analyses has been applied to the Montevideo metropolitan area of Uruguay. The results indicate that there is only a very slight overlap between the locations captured in user-generated images and the tourist attractions promoted in institutional materials and travel guides. A considerable number of photographed locations do not constitute official attractions, thus suggesting a greater presence of visitors in the whole metropolitan area and that the tourist city is more 
extensive than that traditionally promoted. This situation has potential benefits in terms of identifying new attractions or improving the management of future projects.

Keywords: territorial distribution; institutional tourism materials; travel guides; social networks; Instagram; tourist attractions

\author{
Sumario \\ 1. Introducción 4. Resultados \\ 2. Revisión bibliográfica 5. Conclusiones \\ 3. Metodología Referencias bibliográficas
}

\title{
1. Introducción
}

La imagen de una localidad ha constituido tradicionalmente un elemento de primer orden de la práctica turística (Garrod, 2008; Mackay y Couldwell, 2004), una situación que se ha visto enormemente reforzada por la eclosión de redes sociales basadas en fotografías. Gracias a la mayor accesibilidad y a la posibilidad de geolocalizarlas, se ha podido analizar la imagen de varios territorios desde nuevas ópticas (Kádár y Gede, 2013: 79; Ahas et al., 2007).

Pese a persistir algunos problemas metodológicos, especialmente los relacionados con la selección previa de imágenes realizada por el usuario antes de subir los contenidos a internet (Donaire et al., 2014: 26), son varios los trabajos que se han servido de esta fuente para analizar el comportamiento turístico. A modo de ejemplo podemos citar estudios recientes focalizados en el proceso de creación de la imagen (Stylianou-Lamber, 2012), su temática (Donaire et al., 2014), la experiencia de los usuarios (Hochman y Manovich, 2013) o las relaciones entre contenido y localización de la imagen (Ji et al., 2011; Crandall y Snavely, 2012).

Las imágenes procedentes de las redes sociales tienden, no obstante, a ser el único instrumento de análisis de un buen número de estos estudios recientes. Se obvia así que la representación de un territorio obedece a una casuística más amplia y multidimensional (Paül i Agustí, 2009; Gallarza et al., 2002). Hunter (2016: 222) señala que la imagen de estos espacios es un constructo basado en tres aspectos: 1) imágenes de destino o paisaje turístico; 2) imagen de destino proyectada, que asimila a campañas de marketing; 3) imagen percibida del destino o efectos combinados de la experiencia de marketing y del destino real en el visitante. Así, para reconstruir la representación de un territorio, la información disponible en las redes sociales no es suficiente. Se debería analizar tanto la imagen proyectada como la percibida (Galí y Donaire, 2015: 893), una comparación usada con éxito en estudios que han abordado aspectos como el análisis semiótico de la representación visual de Seúl (Hunter, 2016), la decisión de comprar por parte del cliente (Grønflaten, 2009) o la planificación y el cumplimiento de las expectativas de los viajes turísticos (Seabra et 
al., 2007). Los resultados de estos estudios muestran diferencias significativas entre ambas imágenes.

El presente trabajo pretende desarrollar dichas diferencias para identificar comportamientos espaciales distintos en función del canal de proyección de la imagen. En este sentido, se busca identificar las diferencias espaciales de la imagen turística en función de si su difusión obedece a herramientas de marketing o bien a la experiencia del visitante (Hall y Page, 2014; Gumuchian, 1991). Concretamente, el artículo analizará la localización de los recursos turísticos descritos en el material institucional, las guías turísticas y los contenidos generados por los usuarios en la red social Instagram. Para ello se estudiará el tratamiento que se hace del área metropolitana de Montevideo (Uruguay). El objetivo es señalar las similitudes y las diferencias de localización espacial incorporadas en las distintas fuentes para apuntar las consecuencias que este aspecto puede tener en la promoción turística del territorio.

\section{Revisión bibliográfica}

\subsection{La imagen del destino}

La creación de la imagen de un destino continúa siendo uno de los temas básicos de la investigación turística (Hunter, 2016). Se puede definir como una representación individual, compleja, creada por organizaciones, residentes o agentes anónimos (Tasci y Gartner, 2007). Tiende a tratarse de una representación individual de conocimiento, sentimientos y percepciones que afectan a un destino (Fakeye y Crompton, 1991). Algunos autores han afirmado que la imagen de un destino es un "concepto nebuloso" (Hughes y Allen, 2008: 30). Otros apuntan que la promoción turística no desempeña un papel clave en su formación (Govers y Go, 2004). Sin embargo, la mayoría de los autores coincide en considerar que se trata de un concepto multidimensional que debe ser objeto de análisis (Gallarza et al., 2002).

Las imágenes nos permiten examinar la representación de un lugar (Yan y Santos, 2009; Chon, 1990) y constituyen una parte importante de la proyección de un destino (MacKay y Couldwell, 2004; MacKay y Fesenmaier, 1997). Ahora bien, tienen una componente de sinécdoque, es decir, una parte de ellas puede asociarse al todo o viceversa. Así, la representación en una fotografía puede resumir la complejidad de la ciudad visitada y hacerla asequible al turista (Smith, 2005).

Las imágenes reproducen símbolos con significados que han sido socialmente construidos y difundidos. Se trata de percepciones individuales y reflexiones subjetivas que se han formado en la mente (Galí y Donaire, 2015). El estudio de la imagen es, por lo tanto, complejo, con muchas facetas intangibles que dependen de la percepción o la experiencia que cada autor le asigne (Staszak, 2014: 597). Como resultado, la comparación de la imagen promocionada por los agentes sociales de una ciudad con la reproducida en las fotografías tomadas por los turistas puede proporcionar información relevante para comprender las diferentes formas como se interpreta un espacio. 
A esta complejidad debemos añadir otro aspecto. El turista únicamente tiende a reconocer un número extremadamente limitado de espacios del destino que visita. Una situación que generalmente se contrapone con la presencia, en este mismo destino, de un número potencialmente elevado de recursos turísticos. Así, la distribución de los atractivos tiende a dibujar lo que Pan y Li (2011) han señalado como "cola larga». Como muestran, la imagen turística de China tiende a focalizarse en unos pocos términos, que se corresponderían con los nodos principales de una visita turística (Xi'an, Beijing, Gran Muralla). Una vez superadas estas localizaciones frecuentes, reconocidas por todos los turistas, la diversidad de espacios identificados aumenta, pero disminuye el número de personas que es capaz de reconocerlos.

La fijación de estos atractivos en la representación mental colectiva depende de una serie de filtros (Agapito et al., 2013: 471) y de como los turistas interactúan con la imagen del destino antes, durante y después de sus visitas (Tasci y Gartner, 2007). Estas interacciones pueden dividirse en dos categorías principales: «imagen proyectada que se relaciona con aquellas imágenes creadas por diferentes agentes para generar una cierta impresión de destinos y lugares» e «imágenes percibidas, que son el conjunto de valores, ideas e ideologías relacionadas con experiencias, conocimientos y percepciones individuales y subjetivas construidas en la mente de los turistas» (Galí y Donaire, 2015: 893). Dos categorías que ocasionalmente pueden interactuar entre sí para crear una imagen de destino «que no se proyecta ni se percibe, sino que se construye mediante la acumulación de acciones individuales» (Hunter, 2016: 223). Este tipo de enfoque, que combina imagen proyectada e imagen percibida, es la que seguiremos en el presente artículo.

\subsection{La imagen turistica en línea y sin conexión}

En la sociedad moderna, el movimiento de personas, objetos, bienes, capitales e ideas se ha acelerado tanto cuantitativa como cualitativamente. En este contexto, los turistas ya no se ven como meros espectadores, sino que son también actores que interactúan con los lugares que visitan (Larsen et al., 2007), lo cual contribuye a generar un cambio en las percepciones de los destinos (Coleman y Crang, 2002).

La literatura existente ha tendido a considerar que los turistas reproducían en sus retratos imágenes vistas en guías o en sitios web (Caton y Santos, 2008). En cambio, los estudios más recientes otorgan a los turistas un papel activo, capaz de dar una visión única a los espacios y a las personas fotografiados (Stylianou-Lamber, 2012: 1817). La creciente diversidad de formas en que los turistas actúan, sus razones para visitar diferentes lugares y la facilidad con la que los pueden captar han producido nuevos tipos de comportamiento (Stepchenkova y Zhan, 2013).

En este contexto, la fotografía digital ha supuesto un notable aumento en el número de imágenes realizadas y en su difusión. Estas ya no se comparten en contextos estrictamente privados, sino que son difundidas en redes sociales y se transforman en un elemento más de la imagen del destino (Hunter, 
2012). Las comunidades virtuales adquieren así una influencia significativa en el turismo, con lo que gozan de más credibilidad que los medios tradicionales (Katsoni, 2014: 109). Se incorpora, así, una nueva categoría de instantáneas, que permite crear matices sobre el destino promocionado. Mientras las fuentes tradicionales, como folletos y guías, aspiraban a ser objetivas (Wolcott, 1995) o responder a criterios comerciales (Mackay y Fesenmaier, 2000), la imagen en línea permite disponer de una visión más personal, basada en la experiencia (Hunter, 2016: 223). La incorporación de nuevos actores permite, en definitiva, identificar nuevos atributos de la imagen de un destino (Stewart, 2005).

\subsection{La localización de actividad turistica}

El nuevo papel del turista, como creador y difusor activo de instantáneas a partir de sus propias motivaciones y expectativas, genera un cambio en los usos del espacio (MacKay y Couldwell, 2004; Coleman y Crang, 2002; Massey, 2001). Las imágenes difundidas por administraciones y guías se complementan con las creadas por los turistas. Se supera la idea de "burbuja turística» caracterizada por la pérdida de valor intrínseco del lugar (Relph, 1976) y se entra en una etapa de path creation, que pone el acento en la importancia de los cambios discontinuos y en el peso que las fuerzas sociales pueden ejercer en el rediseño del espacio físico y los comportamientos del visitante (Brandajs y Soro, 2017: 21-22).

Es habitual que una misma destinación turística comprenda un amplio número de pequeños atractivos difíciles de identificar (Lew y McKercher, 2006). La combinación de información de fuentes diversas y su localización espacial permite analizar y caracterizar los espacios (Paül i Agustí, 2014). Tradicionalmente, la descripción de las áreas urbanas, en particular sus centros, ha tendido a basarse en una aproximación cuantitativa focalizada en aspectos como la ocupación del espacio o el uso del suelo. En el caso del turismo, la identificación de los espacios más relevantes se ha asentado en la densidad de ocupación de las actividades turísticas o los flujos de visitantes (Marmolejo y Cerdà Troncoso, 2017). Sin embargo, varios estudios han señalado la necesidad de incorporar aspectos más cualitativos para recoger la complejidad de la ciudad (Shoval y Raveh, 2004), entre ellos la imagen del destino (Hollinshead, 2009; Ryan y Cave, 2005; Brown, 1995).

El geoetiquetado o geotagging de imágenes ha permitido realizar nuevos enfoques sobre la localización espacial de la actividad turística (Raun et al., 2016; Shoval y Isaacson, 2007), unos trabajos todavía poco presentes en la literatura académica (Schwartz y Halegoua, 2015: 1645). Pese a ello, son varios los autores que han señalado su potencial como herramienta para analizar la localización de la actividad turística (Dickinson et al., 2014: 85). Kwan (2002) señalaba que una aproximación cualitativa del trabajo digital permitía comprender mejor las experiencias urbanas.

Varios autores apuntan a las redes sociales como instrumentos capaces de identificar nuevas relaciones entre lo físico y lo digital, lo que mejora el conoci- 
miento del espacio visitado (García-Palomares et al., 2015; Zhou, 2014; Gordon y De Souza e Silva, 2011). Otros investigadores, en cambio, se han centrado en una visión más crítica, analizando el modo como las tecnologías móviles reconfiguran los espacios turísticos (Germann Molz y Paris, 2013) o pueden incluso fomentar la exclusión y la fragmentación de los espacios (Hannam et al., 2014).

La localización de las distintas instantáneas proyectadas por un destino permite incorporar un elemento cualitativo al debate, mostrando aspectos como la imagen que el espacio visitado pretende difundir o las experiencias vividas por los turistas (Balomenou y Garrod, 2014). Este es el objetivo principal del artículo, comparar la localización espacial de las imágenes proyectadas por un mismo destino según tres fuentes: folletos turísticos oficiales, guías de viaje y contenido generado por los usuarios.

\section{Metodología}

\section{1. Ámbito de estudio}

En la presente investigación nos hemos focalizado en el departamento de Montevideo. Montevideo es la capital de la República Oriental del Uruguay. Según datos del censo de 2011, el departamento de Montevideo concentra 1,3 millones de habitantes de los 3,4 millones del país (un 38\%). Ocupa $525 \mathrm{~km}^{2}$, lo que representa poco menos del 0,3\% de la superficie de Uruguay. El departamento de Montevideo presenta un doble perfil: urbano y rural. Aproximadamente 192 $\mathrm{km}^{2}$ son superficie urbana. Administrativamente, el departamento corresponde a la Intendencia de Montevideo, que se subdivide en 8 municipios.

La actividad turística presenta un peso relevante en Uruguay. En 2015 significó aproximadamente un 7\% de su PIB. Durante el año 2016 el país tuvo 3,3 millones de llegadas de visitantes extranjeros, cuyo origen principal es Argentina y Brasil. En cuanto al destino elegido prioritariamente, Montevideo es el punto principal de atracción, donde acude el 31,6\% de los turistas del país (Sosa, 2016). Cabe señalar igualmente que Montevideo es un destacado puerto de cruceros donde durante la temporada 2015-2016 desembarcaron 196.000 personas.

Este conjunto de datos hace que Montevideo pueda considerarse un área excelente para valorar el comportamiento espacial de sus visitantes. La ciudad acoge un elevado flujo de varias tipologías y nacionalidades, además, dispone de múltiples atractivos patrimoniales, naturales y paisajísticos, un buen nivel de servicios y ferias y festivales relevantes, unas características que permiten que las observaciones realizadas puedan ser extrapolables a otras localidades.

\subsection{Recopilación y análisis de datos}

La información base para el presente estudio procede de tres fuentes: material editado por las instituciones públicas, guías turísticas e imágenes generadas por los usuarios. 
El material editado por las instituciones públicas se recopiló sobre el terreno durante los meses de febrero y marzo de 2017. A lo largo este período se visitaron dos veces cada una de las seis oficinas de turismo existentes en el área metropolitana (tres gestionadas por el Ministerio de Turismo, dos de la Intendencia de Montevideo y una municipal). Siguiendo la metodología de Stylianou-Lamber (2012: 1824) se consideró que la muestra estaba completa, y en consecuencia era representativa, cuando las nuevas visitas a las oficinas no aportaron nuevo material editado a la muestra. En total se obtuvo el siguiente material:

- Guía de Montevideo: Descubrí Montevideo.

- Mapa turístico de Montevideo (3 versiones) y del barrio de Prado (2 versiones).

- Agenda cultural de Montevideo 2017.

- 12 trípticos dedicados a aspectos concretos de la ciudad.

En cuanto a las guías turísticas, se vaciaron las ediciones más recientes de todas las que había disponibles en el mercado, publicadas en lengua castellana a partir del año 2010: Anaya Touring (Pagella, 2013), Bradt (Burford, 2011), Lonely Planet (Bao, 2015) y Guía Azul (Monreal, 2012) ${ }^{1}$.

Del material editado por las instituciones públicas y de las guías turísticas se realizó un vaciado del conjunto de la información que contenían. Se identificaron los atractivos que se promocionaban, su localización y datos más cuantitativos (número de palabras de la descripción y dimensión de la imagen o del mapa referente al atractivo). Los datos obtenidos se cuantificaron en función de la fórmula propuesta por Serrano e Imbert-Bouchard (2009: 391):

Índice de impacto $=\left(\left(\mathrm{A}^{*} 10 / \mathrm{Amax}\right)^{*} 0,4\right)+\left(\left(\mathrm{B}^{*} 10 / \mathrm{Bmax}\right)^{*} 0,2\right)+\left(\left(\mathrm{C}^{*} 10 /\right.\right.$ $\left.\mathrm{Cmax})^{*} 0,2\right)+\left(\left(\mathrm{D}^{*} 10 / \mathrm{Dmax}\right)^{*} 0,2\right)$

A = Número de palabras de la descripción del atractivo.

$\mathrm{B}=$ Dimensión de las imágenes relacionadas con el atractivo.

$\mathrm{C}=$ Mapa o croquis de localización del atractivo.

$\mathrm{D}=$ Tratamiento objetivo $\mathrm{y} / \mathrm{o}$ subjetivo del atractivo.

Las dos fuentes de información anteriores se podían vaciar en su totalidad, un hecho imposible en la tercera fuente, la red Instagram. Por este motivo fue necesario acotar la información que se quería analizar. Instagram es una red social para compartir imágenes y comentarios asociados, y las imágenes

1. Dado el tiempo transcurrido entre la publicación de alguna de las guías y su análisis, podrían existir algunas evoluciones puntuales en los elementos tratados. Pese a ello, dadas las coincidencias entre las guías analizadas más antiguas y las más recientes, hemos considerado que esta evolución, de existir, sería limitada. 
pueden compartirse de forma pública o privada. En la presente investigación únicamente hemos utilizado las de carácter público, por lo tanto este no es un estudio de todas las fotografías turísticas, sino de aquellas que los usuarios deciden compartir en Instagram.

Instagram permite realizar una búsqueda preliminar de los lugares donde han sido tomadas las instantáneas. En nuestra investigación hemos utilizado tres localizaciones: Montevideo, Ciudad de Montevideo y Uruguay. A pesar de existir otros emplazamientos referentes a barrios o a municipios de la ciudad, los tres topónimos elegidos eran los que presentaban mayor nivel de actividad. Concretamente, Montevideo generaba unas 1.200 fotografías diarias; Ciudad de Montevideo, unas 250, y Uruguay, unas 2.000 al día.

En el presente estudio, para evitar la estacionalidad, hemos analizado las imágenes generadas en dos momentos: del 1 al 15 de noviembre de 2016 y del 8 al 25 de febrero de 2017. La recopilación de la información también siguió la metodología de Stylianou-Lamber (2012: 1824). Se consideró que la muestra era representativa cuando el vaciado de un nuevo día no incorporaba nuevos elementos turísticos a la base. En total se estudiaron unas 107.000 instantáneas, de las cuales 5.488 conforman la muestra. Una cifra a medio camino de la utilizada en otros estudios, como el de Galí y Donaire (2015), basado en 34.200 imágenes de Flickr, o el de Stylianou-Lamber (2012), focalizado en 400 imágenes de Flirck y Picasa.

El primer paso para clasificar las fotografías fue descartar aquellas generadas por los residentes. La selección se realizó a partir de la información disponible en el perfil del usuario. Concretamente:

- Se analizaba la localización del usuario en los últimos quince días, un dato que ofrecía la aplicación. Si se observaba movilidad territorial, se incluían en la muestra.

- Si no existía movilidad, se identificaba la lengua de los escritos y de los comentarios. En caso de no ser en castellano, se incluían.

- En caso de ser en castellano, si el contenido hacía referencia a vacaciones, a actividades de ocio o a movilidad, se incluían. En caso contrario, se descartaba definitivamente.

- Si la identidad del fotógrafo no quedaba suficientemente clara, se descartaba la imagen.

Siguiendo la metodología de Stylianou-Lamber (2012: 1825) para evitar la subjetividad sobre las pautas anteriores, se establecieron una serie de pruebas piloto, en las que participó el autor y un codificador independiente (Camprubí y Coromina, 2016: 138). Se analizaron 20 imágenes. El grado de coincidencia inicial fue del $90 \%$. Después de discutir las diferencias, se homogeneizaron y se clarificaron los conceptos. Cuando se repitió la prueba con nuevas fotografías, la coincidencia en la codificación fue del 95\% y esta codificación permitió identificar que los visitantes eran responsables de un 19,7\% de las instantáneas (un total de 21.082). 
El siguiente filtro fue identificar las imágenes que podían ser localizadas en el mapa. El primer paso se basó en la metodología comentada por Donaire et al. (2014). Se empleó este método por ser objetivo, sistemático y generalista, a fin de garantizar la confiabilidad y la replicabilidad de los estudios (Holsti, 1968). Concretamente se adaptó la idea de eye-catchers. Se considera eye-catchers una ilustración donde el $50 \%$ o más de la imagen está ocupada por un elemento que capta la atención (Pritchard y Morgan, 1995: 28). En nuestro caso, se descartaron aquellas en las que el $50 \%$ o más del espacio estuviese ocupado por elementos que no fuesen territorializables: caras (selfis), detalles, puestas de sol, nubes, etc. Aproximadamente un tercio de ellas correspondían a esta categoría.

En cuanto a las 15.036 fotografías restantes, se buscó su localización en el mapa. Para ello se usaron cuatro vías:

- Comentarios presentes en la aplicación, en los que se identificaban directamente los lugares.

- Reconocimiento de localizaciones en las diversas imágenes (con nombres de comercios, direcciones, etc.).

- Análisis a través de la aplicación Google Images, la cual permite hacer búsquedas por instantánea. Los resultados muestran páginas con fotografías similares, donde a menudo aparece la localización.

- Para las imágenes que no era posible identificar con los métodos anteriores, se contactó con varios especialistas con un elevado conocimiento del ámbito turístico uruguayo.

En el caso de guías y trípticos el proceso anterior no fue necesario, ya que todas las instantáneas se encontraban identificadas en el texto.

Finalmente, se localizaron 11.261 imágenes en un sistema de información geográfico, un $74,9 \%$ de las territorializables colgadas por los visitantes en Instagram en el periodo examinado. Como hemos apuntado, en el presente estudio nos centraremos en las que estaban georreferenciadas del Departamento de Montevideo. Este departamento concentraba una parte importante de las fotografías: 5.488 (un 48,73\% de las de Uruguay).

Para las imágenes creadas por los usuarios, se elaboró un índice de impacto que, adaptándolo a la información de la fuente, respetase el utilizado en las guías y el material institucional.

Índice de impacto $=\left(\left(\mathrm{A}^{*} 10 / \mathrm{Amax}\right)^{*} 0,4\right)+\left(\left(\mathrm{B}^{*} 10 / \mathrm{Bmax}\right)^{*} 0,2\right)+\left(\left(\mathrm{C}^{*} 10 /\right.\right.$ $\left.\mathrm{Cmax})^{*} 0,2\right)+\left(\left(\mathrm{D}^{*} 10 / \mathrm{Dmax}\right)^{*} 0,2\right)$

A = Número de palabras de la explicación.

$\mathrm{B}=$ Número de «me gusta».

$\mathrm{C}=$ Número de etiquetas.

$\mathrm{D}=$ Tratamiento como Top Post $(\mathrm{Dmax}=1)$. 


\subsection{Agregación y cartografía de los datos}

La agregación de los datos se realizó a través de dos métodos. Los cálculos de distancia inversa ponderada (Inverse Distance Weighting - IDW) y el cálculo de la estimación de densidad Kernel (Kernel Density Estimation - KDE).

IDW es un método de interpolación común y usado ampliamente dentro del GIS (Haklay, 2007). Las técnicas de interpolación espacial permiten convertir mediciones discretas en una distribución continua en el espacio. Como toda función de interpolación, IDW opera con un conjunto de puntos muestreados $(\mathrm{L} 1, \mathrm{~L} 2 \ldots, \mathrm{L} n)$ y calcula el valor para una nueva ubicación L. Se elaboran asumiendo explícitamente la suposición que los valores colindantes son más parecidos entre sí que aquellos que están más separados. Este método permite incluir comportamientos excepcionales dentro del conjunto. Es decir, puntos con un índice de impacto elevado dentro de áreas con pocos atractivos.

En el presente estudio las interpolaciones se han realizado sobre el conjunto del área de Montevideo. Para establecer los cálculos se han respetado los valores recomendados por defecto en la herramienta utilizada (ArcGis 10.4.1). Así, las interpolaciones se han establecido a partir de los doce valores espacialmente más próximos. Se han realizado dos IDW (material impreso e Instagram) en función de la localización geográfica de los elementos analizados y se ha obtenido un valor $Z$ de ponderación correspondiente al índice de impacto de cada una de las dos fuentes. Las diferencias observadas se han cartografiado mediante los ráster resultantes.

El uso de cálculos de IDW para identificar comportamientos espaciales es habitual en la literatura académica. En el ámbito del turismo ha sido usada por autores que han identificado el potencial turístico de los espacios rurales (Dona y Popa, 2013), las posibles interrelaciones del turismo con los humedales (Lupei et al., 2017) o la cartografía de emociones en el espacio urbano (Shoval et al., 2018).

El segundo método de cálculo usado ha sido el KDE, un sistema no paramétrico para estimar la función de probabilidad de densidad de una variable aleatoria (Terrell y Scott, 1992). Se basa en un proceso de inferencia de una muestra de puntos conocidos para estimar las densidades locales del conjunto de puntos. Los cálculos se han realizado a partir de los parámetros establecidos por defecto en la herramienta ArcGis 10.4.1, usando el índice de impacto como campo de ponderación.

En los mapas resultantes el valor de la superficie es más alto en la ubicación del punto y disminuye con el aumento de la distancia hasta llegar a cero. Este método permite dar más peso a los puntos más significativos y también penaliza los comportamientos excepcionales. Se trata, en consecuencia, de un buen sistema para sintetizar comportamientos de áreas. Como tal, el KDE ha sido usado en varios trabajos recientes, para analizar el comportamiento turístico (Miah et al., 2017) o delimitar los downtown a través de las etiquetas de Flickr (Hollestein y Purves, 2010). 


\section{Resultados}

\subsection{Presentación}

Un primer aspecto a resaltar es la elevada cifra de atractivos turísticos identificados: un total de 501. Instagram es la fuente con mayor número: 455. El material institucional y las guías turísticas tienen una cantidad similar de atractivos: 173 y 174 , respectivamente (tabla 1 ).

Así, el total de atractivos turísticos identificados en Instagram es más de 2,6 veces el de atractivos del material institucional y del que consta en las guías. En consecuencia, podemos apuntar que el material editado únicamente muestra un número limitado de aspectos que los visitantes consideran de interés fotográfico.

El cruce de los datos de las distintas fuentes también muestra algunas coincidencias interesantes entre los elementos que las distintas fuentes analizadas consideran atractivas. A modo de ejemplo, únicamente el $74 \%$ de los atractivos descritos en el material institucional y el $66,1 \%$ de los de las guías turísticas aparece en Instagram. En consecuencia, podemos considerar que una parte de los elementos promocionados por los canales oficiales y por las guías turísticas no son suficientemente atractivos para que el visitante les dedique una fotografía. En el otro extremo podemos señalar que la mitad de los atractivos identificados únicamente aparecen en Instagram, un aspecto que muestra el potencial de la fuente para localizar estos espacios.

Si valoramos los atractivos citados por las distintas fuentes, las cifras pueden considerarse limitadas. Únicamente 96 de ellos aparecen en el material institucional y las guías turísticas; eso es, un escaso 19,2\% del total de atractivos identificados. Las coincidencias entre cada una de estas dos fuentes e Instagram

Tabla 1. Coincidencias y divergencias entre los atractivos turísticos recopilados en las distintas fuentes

\begin{tabular}{lccc}
\hline & $\begin{array}{c}\text { Número de } \\
\text { atractivos }\end{array}$ & $\begin{array}{c}\text { Porcentaje } \\
\text { sobre } \\
\text { el total }\end{array}$ & $\begin{array}{c}\text { Porcentaje de } \\
\text { imágenes en } \\
\text { Instagram }\end{array}$ \\
\hline Material institucional & 173 & 34,5 & 74,0 \\
Guías turísticas & 174 & 34,7 & 66,1 \\
Imágenes en Instagram & 455 & 90,8 & 100 \\
Citados en alguna de las fuentes & 501 & 100 & \\
Citado en material institucional y en guías turísticas* & 96 & 19,2 & \\
Citado en material institucional y en Instagram & 147 & 29,3 & \\
Citado en guías turísticas y en Instagram & 147 & 29,3 & \\
Citado en material institucional, en guías turísticas y en Instagram & 89 & 17,8 & \\
Citado únicamente en Instagram & 250 & 49,9 & \\
\hline
\end{tabular}

* Podemos considerar que estos 96 puntos, únicamente identificados en guías y material institucional pero no en Instagram, no han sido objeto de visita. En consecuencia, deberían ser considerados formalmente como recursos turísticos. Según Navarro (2015: 351): «Existen recursos turísticos que no equivalen a atractivos turísticos [...] Son relevantes, pero no provocan un viaje».

Fuente: elaboración propia. 
son mayores: 147 (un 29,3\%) de cada fuente, no necesariamente los mismos. Significativamente solo encontramos 89 atractivos citados en las tres fuentes analizadas (el 17,8\% del total de los identificados).

Estos datos nos permiten asimilar la imagen del área de Montevideo al concepto de cola larga (Pan y Li, 2011: 132). El material institucional y las guías turísticas promocionarían mayoritariamente los espacios más conocidos, en cambio las imágenes de Instagram añadirían atractivos complementarios. Las tres fuentes juntas muestran una imagen turística de la ciudad, diversa y variada. Sin un análisis de Instagram, la imagen turística de la ciudad queda claramente difuminada.

\subsection{Localización de los atractivos}

Una vez identificados los atractivos podemos analizar su distribución territorial. Los distintos atractivos enumerados en el texto han sido cartografiados en la imagen 1. La información de las distintas fuentes analizadas se ha representado en las imágenes del material institucional (imagen 2), de las guías turísticas (imagen 3) y las generadas por los usuarios (imagen 4).

Como hemos apuntado anteriormente, el material institucional era el que identificaba un número menor de atractivos (imagen 2). Además, estos atrac-

Imagen 1. Localización de los atractivos turísticos enumerados en el texto

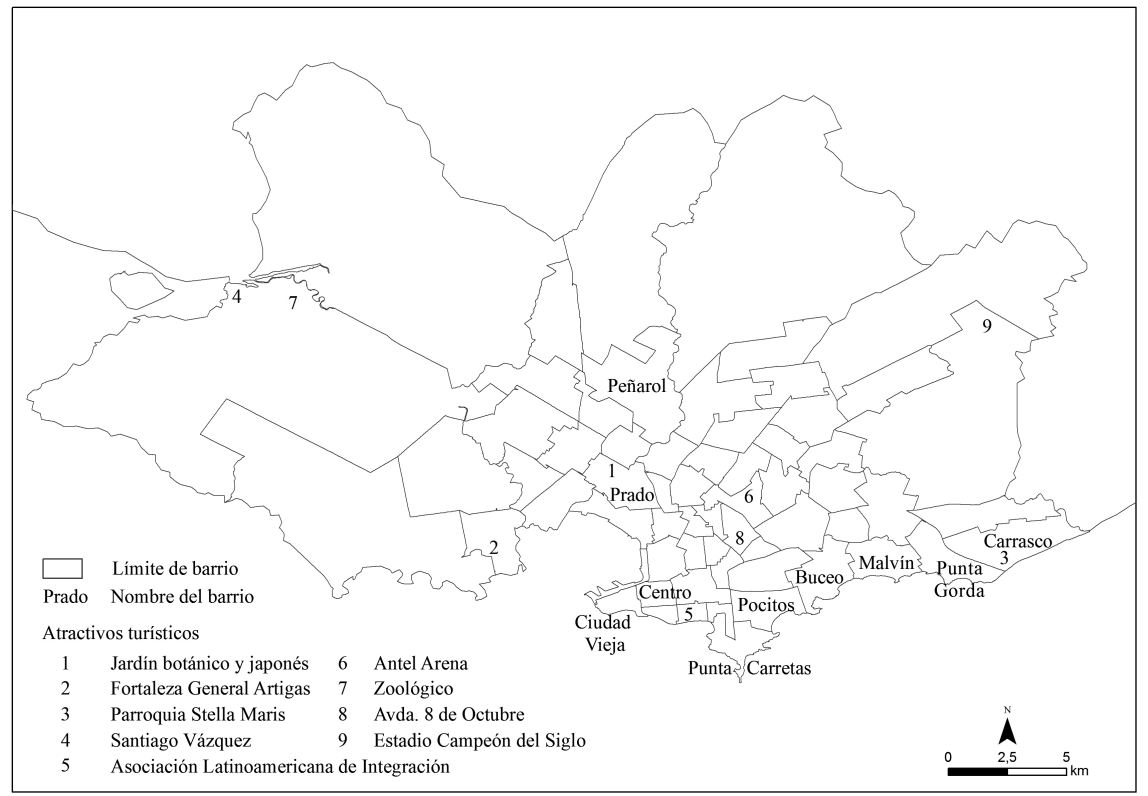

Fuente: elaboración propia. Base cartográfica Licencia de Datos Abiertos - Uruguay, Intendencia de Montevideo. 
Imagen 2. Atractivos identificados en el material institucional (índice de impacto)

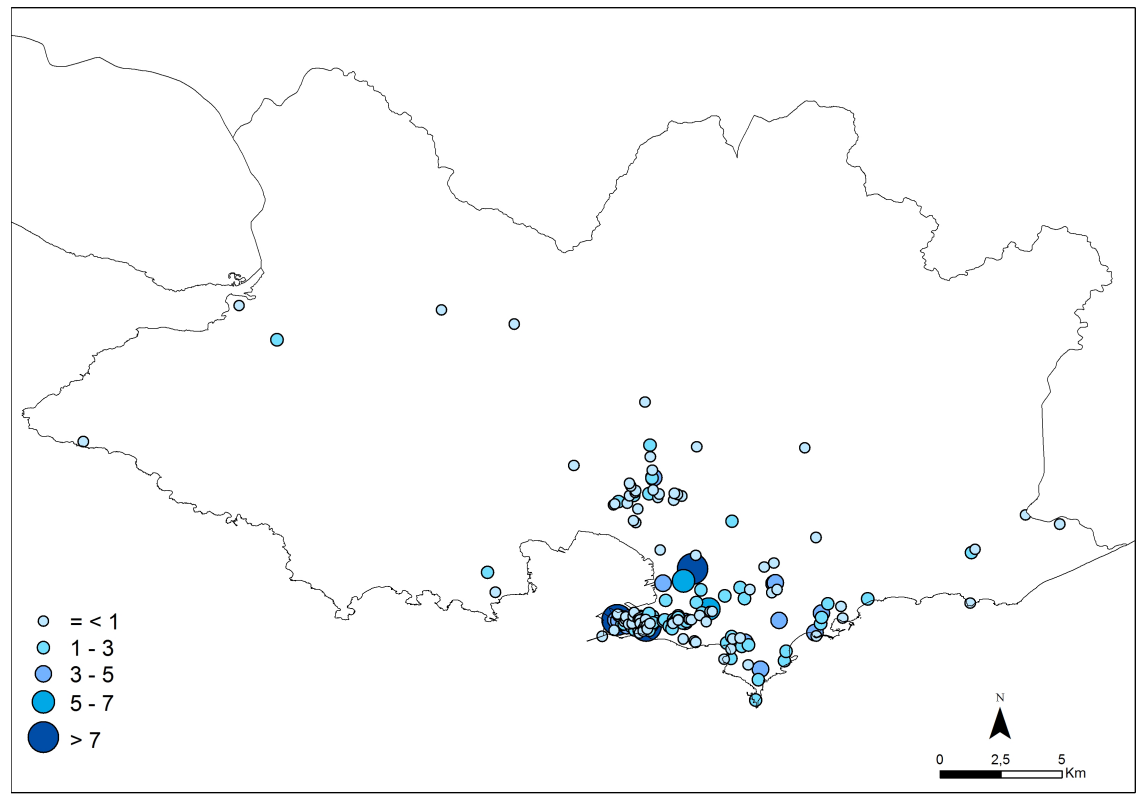

Fuente: elaboración propia. Base cartográfica INE Uruguay.

tivos tendían a una elevada concentración en el centro del área analizada, alrededor de los barrios de Ciudad Vieja (centro histórico de la ciudad) y Centro (principal eje comercial). Fuera de este espacio únicamente encontramos dos áreas con volúmenes importantes de atractivos. Una agrupación de ellos al norte de la zona central (barrio del Prado, creado por la aristocracia entre finales del siglo XIX y principios del XX) y una parte del litoral de la ciudad (barrios de Punta Carretas y Pocitos).

Así mismo, el índice de impacto de los atractivos tiende a ser muy limitado. Solo unos pocos de ellos salen en múltiples publicaciones y muestran un índice de impacto elevado (presencia de fotografía, explicación detallada, etc.), un hecho que remite nuevamente al concepto de cola larga. De hecho, solo 5 de las 173 vistas identificadas en el material institucional aparecen en más de cinco publicaciones y tienen un índice de impacto superior a $6^{2}$. Estos seis atractivos se encuentran todos ellos en la zona central. La mayoría de los descritos en el material institucional aparecen en una única publicación y muestran un índice de impacto claramente inferior a 0,5 . Por lo tanto, podemos observar una concentración importante, tanto territorial como a nivel de la calidad de la información.

2. Teatro Solís, Mercado del Puerto, Mercado Agrícola, Palacio Legislativo y Feria de Tristan Narvaja. 
Imagen 3. Atractivos identificados en las guías turísticas (índice de impacto)

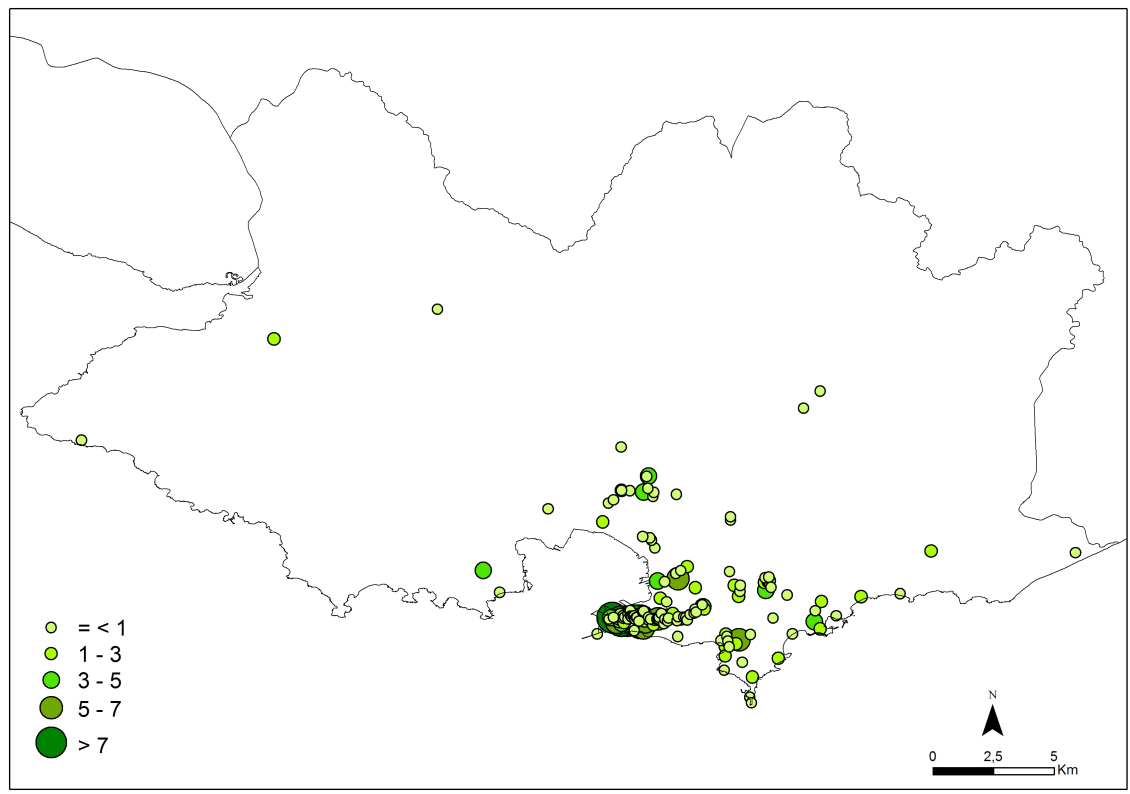

Fuente: elaboración propia. Base cartográfica INE Uruguay.

Si analizamos las guías turísticas (imagen 3), encontramos un patrón similar. La fuente identifica un número parecido de atractivos, con una distribución claramente comparable a la del material institucional. Territorialmente los atractivos de las guías turísticas tienden a localizarse en los mismos puntos que el aspecto promocionado en el material institucional. Lo mismo podemos decir del índice de impacto, que tiende a coincidir. Si realizamos una correlación entre los valores de las dos fuentes, el resultado obtenido se sitúa en 0,646, con un nivel de confianza de un $95 \%$, margen de error de un $5 \%$ y una correlación significativa al 99,9\% $(p<0,01)$. Los datos nos indican, así, una correlación positiva entre las dos fuentes. Además, debemos apuntar que, tal como sucedía con el material promocional, la mayoría de vistas solo se incluyen en una única guía. Únicamente siete de ellas aparecen en todas las guías ${ }^{3}$ y, a nivel de índice de impacto, solamente seis tienen un valor superior a $6^{4}$. Por lo tanto, podemos apuntar que las fuentes oficiales y las guías turísticas tienden a promocionar espacios similares. La distribución de los atractivos es distinta en las imágenes generadas por los usuarios (imagen 4). Las áreas que en las fuentes anteriores concentraban el

3. Mercado del Puerto, Museo de las Artes Decorativas, Museo Histórico Nacional, Plaza Matriz, Teatro Solís, Palacio Salvo y Museo Nacional de Artes Visuales.

4. Plaza de la Independencia, Mercado del Puerto, Museo Torres García, Museo Histórico Nacional, Museo de Artes Decorativas y Teatro Solís. 
Imagen 4. Atractivos identificados en las imágenes de los usuarios (índice de impacto)

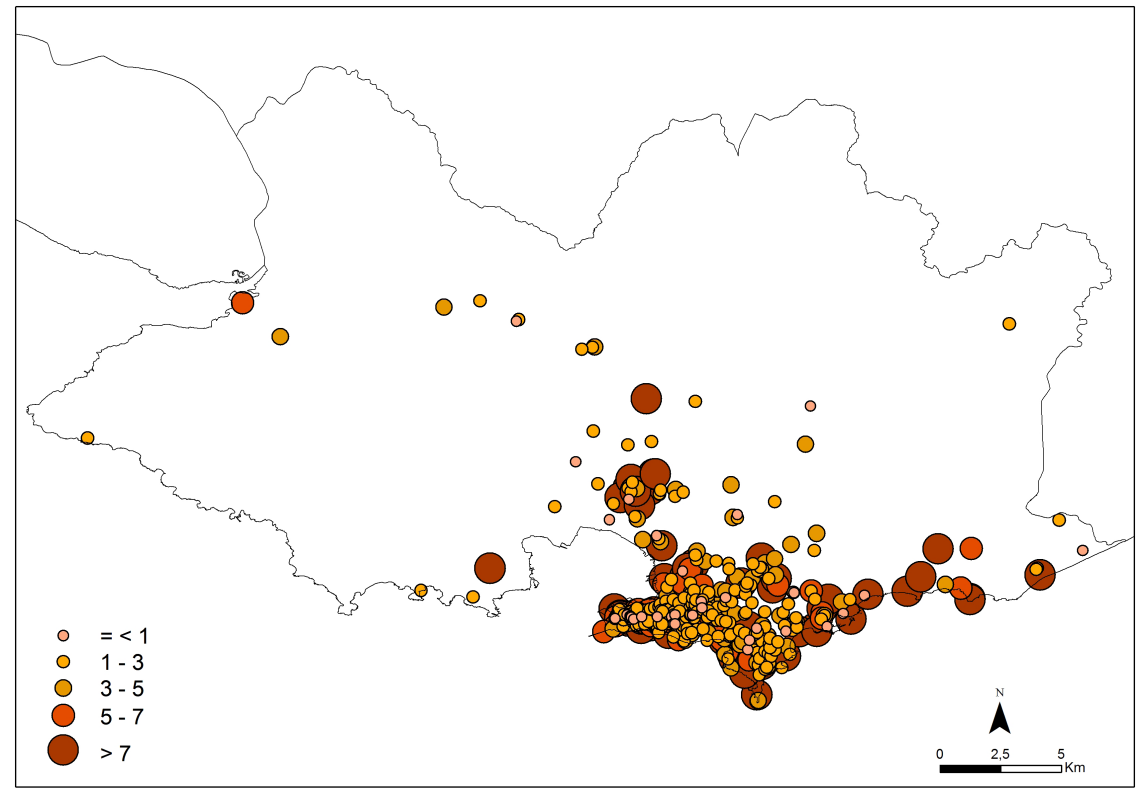

Fuente: elaboración propia. Base cartográfica INE Uruguay.

mayor número de atractivos tienden a coincidir con zonas con fuerte presencia de imágenes creadas por los usuarios. Ahora bien, en estos espacios la densidad de puntos de las imágenes procedentes de Instagram es más alta. En el resto del área de estudio la presencia de las imágenes de los usuarios se encuentra mucho más repartida que en las fuentes anteriores. De hecho, en muchos espacios solo constatamos la presencia de imágenes creadas por los usuarios. Podemos citar, a modo de ejemplo, una distribución más extensa de los atractivos en el litoral de la ciudad (barrios del este, como Malvín, Punta Gorda y Carrasco), así como una mayor difusión de los atractivos alrededor del espacio urbano central.

La mayor distribución territorial de los atractivos se observa también en la intensidad. Los índices de impacto de las imágenes de los usuarios tienden a ser superiores. El número de atractivos que únicamente disponen de una o dos fotografías es relativamente bajo (un 25,5\% de los casos). En cambio, hasta 14 atractivos aparecen con más de 20 fotografías $^{5}$. Pese a que 12 de estos 14 atractivos se encuentran en los barrios centrales, los usuarios también dan relevancia a elementos situados fuera del espacio central, especialmente jardines (botánico y japonés), centros comerciales o algunos elementos patrimoniales (la estación

5. Mercado del Puerto, Plaza de Zabala, Plaza de Matriz, Cabildo de Montevideo, Teatro Solís, Casa de Gobierno, Plaza de la Independencia, Palacio Salvo, Torre Antel, Plaza Fabini, Estadio Centenario, Cartel de Montevideo, Jardín Botánico y Jardín Japonés. 
de Peñarol o la fortaleza General Artigas). Elementos todos ellos escasamente representados en el material promocional institucional y en las guías turísticas.

Con los datos de localización y de índice de impacto podemos señalar que las imágenes institucionales y de las guías turísticas tienden a mostrar coincidencias importantes en los lugares que promocionan, pero no ocurre lo mismo con las imágenes creadas por los usuarios. Por lo tanto, podemos apuntar que los atractivos que fotografían los visitantes que cuelgan sus imágenes en Instagram tienden a presentar una distribución claramente diferenciada y más amplia que en las dos fuentes anteriores.

\subsection{Coincidencias y divergencias de los atractivos en función de la fuente}

La comparación de las tres fuentes anteriores en un único mapa permite obtener una imagen de síntesis de las diferencias existentes en función del medio analizado. Dada la similitud comentada anteriormente entre la distribución de los atractivos descritos en el material institucional y en las guías turísticas (material impreso), hemos tratado estas dos fuentes de forma homogénea.

La imagen 5 interpola los valores sobre la base de un cálculo IDW, comparando los diferenciales en los valores de los índices de impacto de las imágenes generadas por los usuarios con el del material impreso. Los resultados muestran como las fotografías generadas por los usuarios presentan una distribución

Imagen 5. Distancia inversa ponderada y calculadora ráster (índice de impacto)

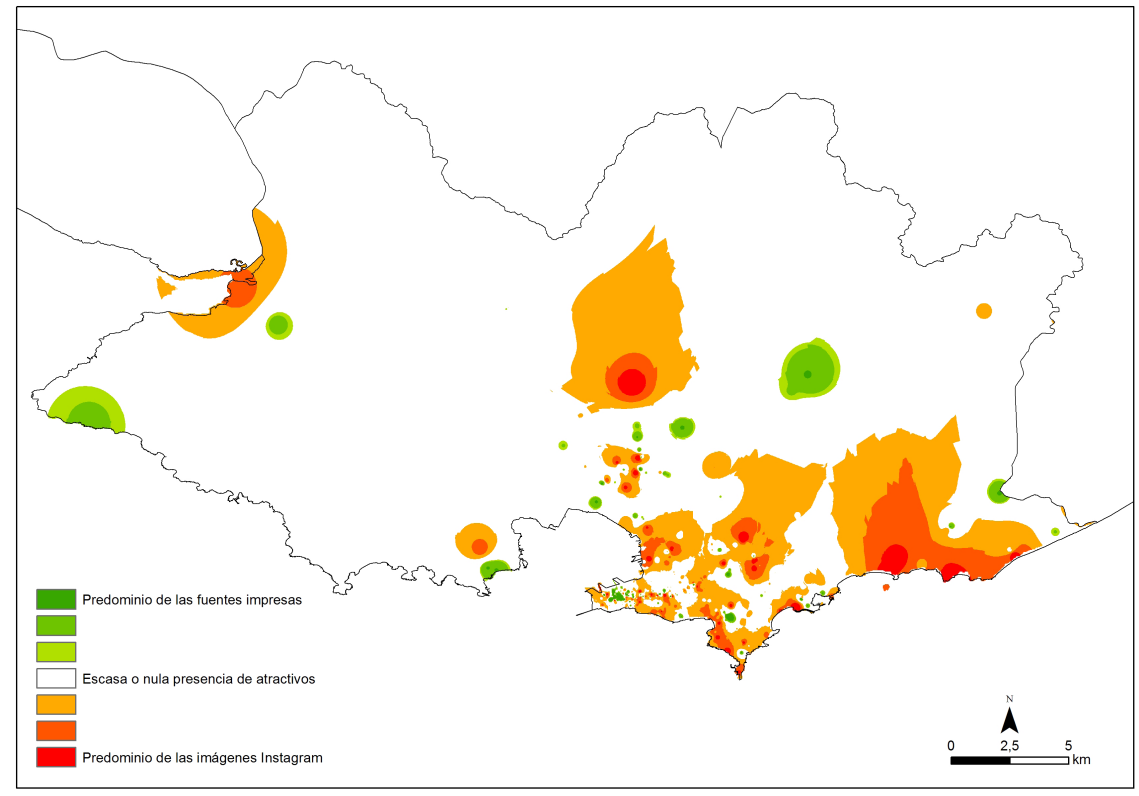

Fuente: SCT SIG de la Universitat de Lleida a partir de datos del autor. Base cartográfica INE Uruguay. 
Imagen 6. Estimación de densidad Kernel de los atractivos en fuentes impresas (índice de impacto)

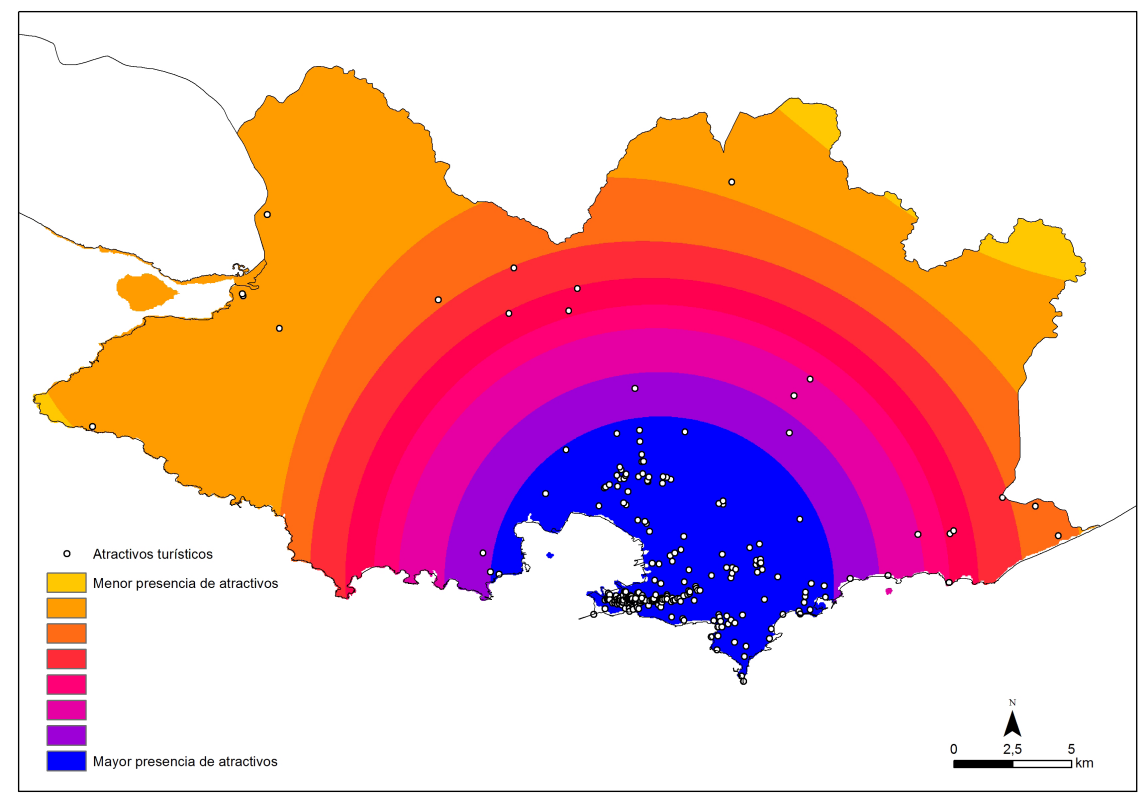

Fuente: SCT SIG de la Universitat de Lleida a partir de datos del autor. Base cartográfica INE Uruguay.

claramente más amplia. Concretamente, en un 17,2\% de la superficie del área metropolitana los atractivos más claramente representados son los creados por los usuarios de Instagram. Se trata generalmente de espacios próximos al núcleo urbano fotografiados con asiduidad, pero que tienen una escasa presencia en el material impreso.

Los atractivos promocionados de forma predominante por las fuentes impresas únicamente son mayoritarios en un 9,4\% de la superficie metropolitana. Se trata básicamente de dos tipologías: elementos muy puntuales del centro histórico (sedes de organismos internacionales como la Asociación Latinoamericana de Integración) o elementos patrimoniales (parroquia Stella Maris) y equipamientos (futuro Antel Arena) de zonas alejadas del núcleo principal. En ambos casos observamos una muy limitada presencia en Instagram de imágenes de estos atractivos. En este sentido deberíamos preguntarnos hasta qué punto es efectiva una promoción turística que no consigue generar fotografías de los visitantes potenciales.

En un 26,9\% de la superficie metropolitana existe cierto equilibrio entre las fuentes analizadas. Pese a que, en términos generales, observamos en el grupo una mayor representación de imágenes de Instagram que de fuentes impresas, las diferencias en los índices de impacto no permiten establecer un claro predominio de una de las fuentes. Se trata, básicamente, de atractivos próximos al 
centro urbano, con unos índices de impacto comparables del material impreso e Instagram.

Finalmente, es importante destacar que en un $46,5 \%$ de la superficie metropolitana ninguna de las tres fuentes analizadas señala la existencia de atractivo turístico.

En consecuencia, podemos considerar que existen diferencias significativas entre la distribución territorial de los atractivos del material promocional y las imágenes de los usuarios, las cuales muestran una distribución más amplia de los atractivos, lo que señalaría puntos con potencial turístico y una escasa presencia en los medios tradicionales. En cambio, las imágenes del material impreso tienden a presentar una distribución más próxima al centro y coinciden únicamente de forma parcial con la imagen de los usuarios.

El segundo método de síntesis se basa en un cálculo de la estimación de densidad Kernel. La imagen 6 muestra la intensidad en la distribución de los valores del material impreso. Según estos datos, la mayor concentración de atractivos turísticos se situaría en un área de unos cuatro quilómetros de radio alrededor del barrio de Centro. A partir de este punto, el índice de impacto de los atractivos descritos va disminuyendo de manera prácticamente constante.

La zona principal se complementaría con una primera corona, de unos 2 quilómetros de radio alrededor de la principal, en la que se obtienen valores elevadores. Esta corona incluiría los barrios de Prado y una parte del litoral (barrio de Pocitos). La intensidad de los valores apuntaría a una zona secundaria que complementaría la principal.

Las otras zonas del área metropolitana presentan un número muy limitado de atractivos, lo que genera que prácticamente no se constate ninguna variación significativa en la concentración de los atractivos. Únicamente observamos una excepción: vemos un ensanchamiento en la zona oeste de la corona más alejada del centro. Este hecho se relaciona con la existencia de dos espacios ampliamente presentes en el material promocional: el núcleo de Santiago Vázquez y el Zoológico Parque Lecocq.

La situación es más compleja en el caso de las fotografías generadas por los usuarios (imagen 7). Si aplicamos el cálculo anterior, los resultados difieren claramente.

La primera corona, la que concentraría los valores más elevados, amplía notablemente su extensión. Pasa de aproximadamente 4 quilómetros de radio en las fuentes impresas a 11,5 en las fuentes creadas por los usuarios. La ciudad de Montevideo sigue siendo la zona con mayor atractivo. Ahora bien, su área de influencia aumenta e incorpora el conjunto de la bahía y buena parte del litoral. Destaca, así mismo, la inclusión de una parte significativa del interior: barrio patrimonial de Prado y zonas relacionadas con el área comercial de la avenida 8 de Octubre.

Por contra, las otras coronas obtienen unos valores discretos. Mientras en las fuentes impresas la primera corona convivía con una segunda, que concentraba algunos espacios con elevado potencial turístico, en el caso de las imágenes creadas por los usuarios los valores disminuyen rápidamente. Se dibuja una 
Imagen 7. Estimación de densidad Kernel de los atractivos generados por los usuarios (índice de impacto)

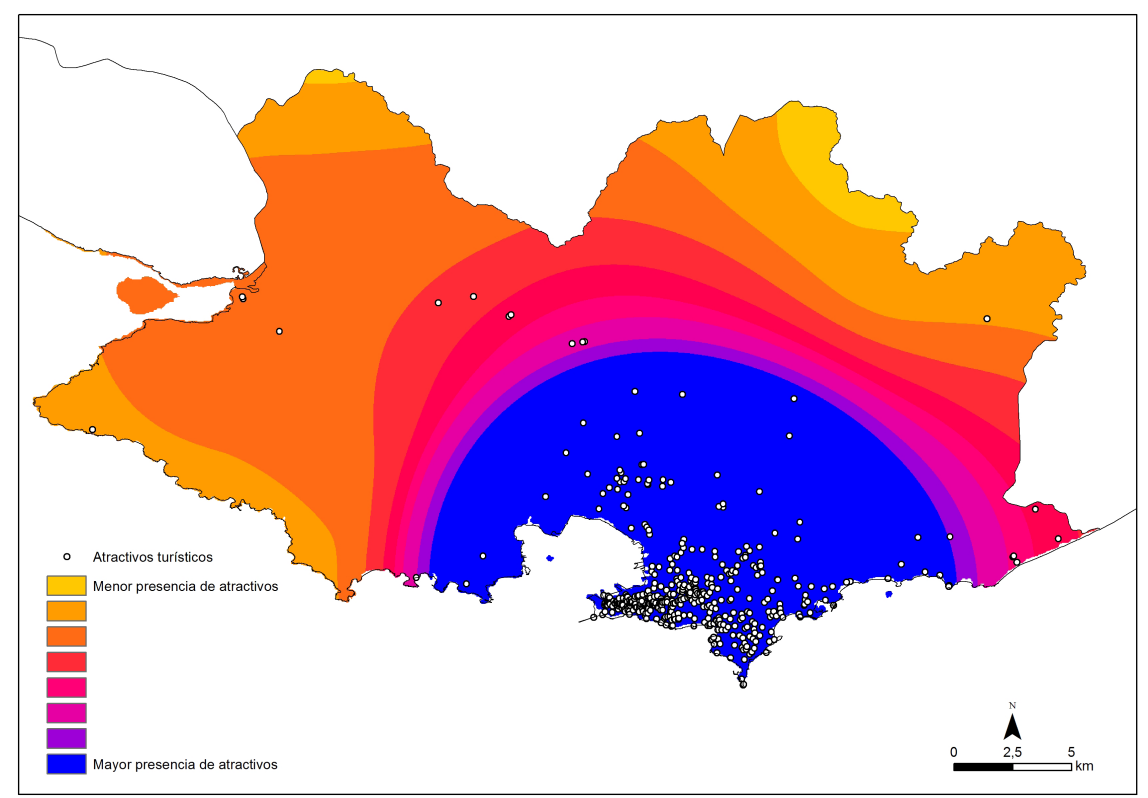

Fuente: SCT SIG de la Universitat de Lleida a partir de datos del autor. Base cartográfica INE Uruguay.

frontera muy clara entre los espacios ampliamente visitados por los usuarios de Instagram y los no visitados por ellos. No existiría término medio. Los usuarios de Instagram o bien tomarían múltiples imágenes de un mismo espacio, lo que justificaría su inclusión en la primera categoría, o bien únicamente unos pocos irían a las zonas más alejadas, lo que implicaría una presencia muy limitada de visitantes potenciales. Esta situación supondría la existencia de un lugar intermedio por el que los visitantes potenciales transitarían, pero en el cual prácticamente no se detendrían a tomar fotografías.

Este aspecto se ve reforzado por unas coronas menos homogéneas que en la imagen 6, lo que indica la presencia puntual de atractivos turísticos de interés para los usuarios de Instagram, especialmente en dos áreas: el litoral al este de la ciudad, donde las franjas se enchanchan, y en ciertos puntos del último de los intervalos, claramente más heterogéneo debido a una mayor localización de atractivos.

La combinación de los resultados anteriores, cartografiados en la imagen 8, sintetiza las diferencias existentes. Los resultados, elaborados a partir de la estimación de densidad Kernel aplicada sobre las dos imágenes ráster anteriores, incluyen el peso de la totalidad de puntos identificados y permite jerarquizar los atractivos del conjunto de la región.

La división de los índices de impacto en intervalos de peso similar señala una clara delimitación de los espacios de interés para los visitantes. En términos 
Imagen 8. Síntesis de los resultados de las fuentes analizadas (estimación de densidad Kernel a partir del diferencial de los índices de impacto)

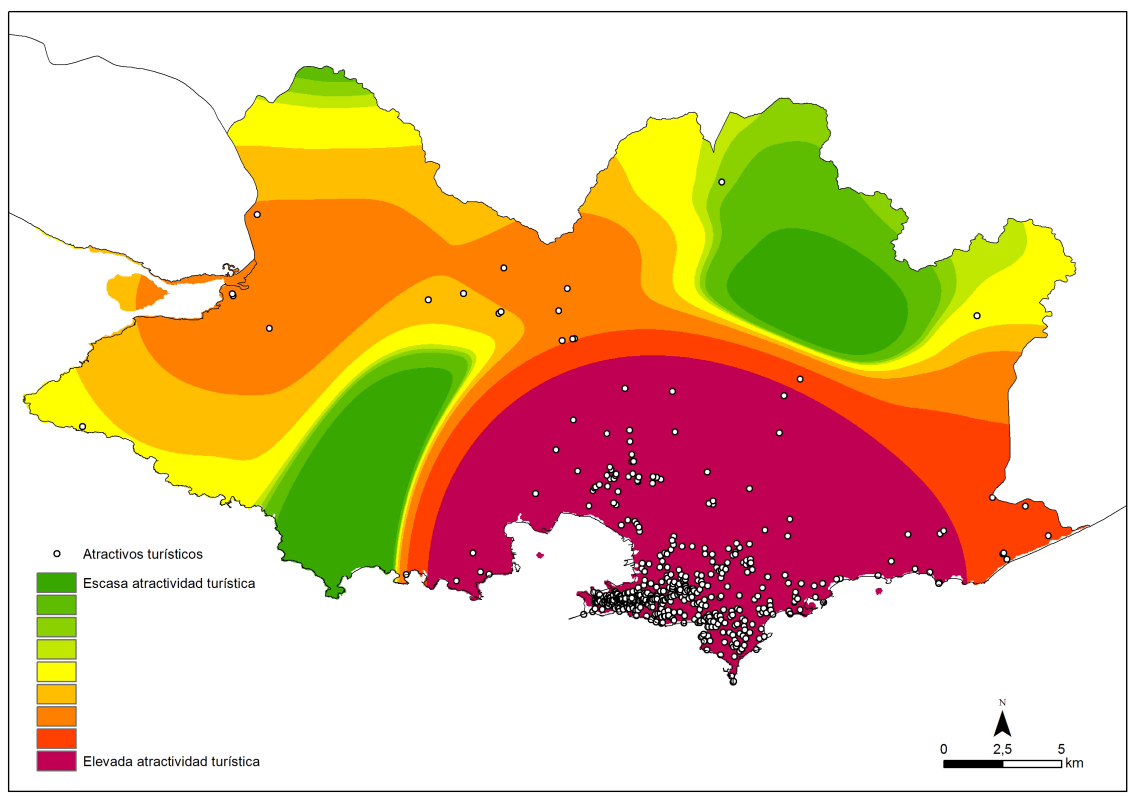

Fuente: SCT SIG de la Universitat de Lleida a partir de datos del autor. Base cartográfica INE Uruguay.

generales, podemos constatar que las zonas con un mayor interés muestran importantes similitudes con las áreas que obtenían valores más altos en Instagram. Esta coincidencia apunta a que dicha aplicación es la fuente predominante en la fijación del índice de impacto de la imagen turística del área de Montevideo, mientras que el material impreso (institucional y guías) únicamente podría matizar la imagen generada por los usuarios.

Así, constatamos una primera corona, de unos 11 quilómetros de radio, que concentra el mayor número de atractivos y valores claramente por encima de la media. Se trata de los alrededores del centro histórico de Montevideo, de una parte significativa del litoral y del núcleo histórico de Prado.

La segunda y la tercera coronas serían más heterogéneas. La segunda únicamente resultaría relevante en la zona este del departamento, donde se ensancharía para incluir varios atractivos de la costa, así como algunos lagos más al interior. En los otros espacios del departamento tendría una presencia residual. En cuanto a la tercera corona, se ensancharía hacía el oeste, incluyendo la zona de Peñarol y de Santiago Vázquez. Estos espacios obtendrían valores alejados de los de la primera corona, aunque serían indicativos de la existencia de ciertos atractivos potenciales.

En los otros espacios la presencia de atractivos turísticos sería más limitada o bien nula. Fuera de las tres coronas enumeradas únicamente encontramos 
uno con valores elevados. Se trata del estadio Campeón del Siglo, al nordeste del departamento. Ahora bien, este elemento sería un ejemplo de como la presencia de uno solo no es suficiente para articular un espacio de atracción relevante.

Los mapas muestran, así, tres aspectos fundamentales. En primer lugar, las diferencias existentes en el tratamiento del espacio turístico en las fuentes analizadas. En segundo lugar, el importante peso de la imagen generada por los usuarios en la creación de la imagen turística del departamento de Montevideo. $\mathrm{Y}$, en tercer lugar, las áreas de influencia que tiene cada conjunto de imágenes. En este sentido, los mapas contribuyen a delimitar los espacios cada vez más amplios en los que se encuentran elementos de interés para el visitante. En el caso del presente trabajo, se trata de puntos suficientemente atractivos para tomar una imagen y compartirla en Instagram. Unos espacios que ya no son los fijados en el material oficial o en las guías turísticas, sino que muestran una distribución territorial claramente mayor y a los que los gestores del turismo deberían estar atentos para identificar potencialidades y debilidades derivadas del cambio de los comportamientos turísticos.

\section{Conclusiones}

A partir de los datos obtenidos, podemos confirmar que la distribución espacial de los atractivos turísticos varía en función de la fuente analizada. Esta diferenciación ha sido señalada en campos como la semiótica (Hunter, 2016), pero tiende a obviarse en aspectos relacionados con el comportamiento espacial del turismo. Se refuerza, de este modo, la necesidad de estudiar dicho comportamiento a partir de herramientas de marketing, contraponiéndolas a investigaciones exclusivamente centradas en la experiencia del visitante (Hall y Page, 2014).

Los resultados se insertan así en el debate actual sobre la importancia de analizar el comportamiento turístico a partir de una aproximación multidimensional, aplicando, en nuestro caso, una componente de distribución espacial. Como hemos mostrado, la reconstrucción espacial de la imagen turística de un territorio variará en función de la fuente analizada, un aspecto que puede tener repercusiones importantes en el estudio del comportamiento turístico.

Analizar la información disponible en las redes sociales no es suficiente para identificar correctamente los comportamientos turísticos. Hemos constatado diferencias significativas entre espacios promocionados activamente en material editado por las instituciones públicas y las guías turísticas y los que aparecen en Instagram. Unas diferencias que algunos estudios actuales tienden a obviar cuando centran sus análisis en los medios digitales, especialmente aquellos (pocos) que permiten un acceso automatizado y libre a la información. Analizar una única fuente o un solo soporte puede condicionar la imagen final que se obtiene del espacio turístico.

Las imágenes creadas por los usuarios presentan una relación muy parcial con las imágenes de guías y el material institucional. En este sentido, los resul- 
tados obtenidos en el área de Montevideo permiten establecer tres grandes diferencias:

- Distinta difusión territorial: predominio del centro histórico en las fuentes impresas y mayor difusión territorial en las imágenes de los usuarios.

- Diferencias en la intensidad: las fuentes impresas tienden a promocionar un número limitado de localizaciones. Las imágenes de Instagram presentan mayor diversidad, lo que las aproxima al concepto de cola larga.

- Escasa coincidencia: las imágenes de los usuarios no incluyen espacios habitualmente representados en los medios impresos. En cambio, lugares sin ninguna promoción en el material impreso sí son ampliamente reproducidos en Instagram.

El análisis de varias fuentes y de diversos soportes permite obtener una imagen más rica, que puede ser usada por los gestores y por los estudiosos del turismo. Tradicionalmente se había señalado que la mirada turística se desarrolla y se construye gracias a múltiples profesionales, y se refuerza gracias a imágenes encontradas en guías, postales y otros materiales promocionales. Como hemos mostrado, las imágenes generadas por los usuarios son también relevantes, pero no por ello deberíamos obviar las otras fuentes.

En este sentido, Instagram demuestra potencialidad como herramienta para conocer el comportamiento territorial de los visitantes, por ello los gestores turísticos no deberían ver este medio únicamente como una herramienta de promoción. Un análisis más amplio de Instagram podría contribuir a mejorar aspectos clave en campos como la gestión (concienciación de los nuevos espacios turísticos) o la promoción (cambiar un enfoque basado en intuiciones de los dirigentes turísticos o en tradiciones a una difusión más dinámica y participativa). Ahora bien, focalizar las decisiones únicamente en este medio puede dar una imagen sesgada, que no incluya espacios promocionados y consolidados por otras fuentes.

El estudio de la localización espacial de la imagen turística a partir de distintas fuentes es un interesante campo de investigación. Un campo que podría ampliarse con la incorporación de otros datos, como los referidos a la oferta (alojamientos, restauración, comercios, servicios turísticos, etc.), a la demanda (visitantes, excursionistas) o a la política turística del espacio analizado. Líneas que podrían contribuir a enriquecer las diferencias identificadas en el presente artículo. Así mismo, también se debería poner especial atención en aspectos como los criterios que llevan a un usuario a compartir una imagen concreta en internet o a acotar hasta qué punto las fotografías de Instagram son representativas del conjunto del turismo y no solo de los usuarios de las redes sociales.

El comportamiento identificado a partir del estudio de las distintas variables demuestra la necesidad de incorporar fuentes diversas al análisis de las zonas turísticas. Una línea de investigación que podría aportar una información muy significativa y que ayudaría a optimizar la gestión del espacio a partir de una mejor identificación de las distintas imágenes proyectadas de un territorio. 


\section{Referencias bibliográficas}

Agapito, Dora; Oomdo Valle, Patrícia y Da Costa Mendes, Júlio (2013). «The cognitive-affective-conative model of destination image: A confirmatory analysis». Journal of Travel \& Tourism Marketing, 30 (5), 471-481. <https://doi.org/10.1080/10548408.2013.803393>

Ahas, Rein; AasA, Anto; Mark, Ülar; TAaVI, Pae y Kull, Ain (2007). «Seasonal Tourism Spaces in Estonia: Case study with mobile positioning data». Tourism Management, 28 (3), 898-910. $<$ https://doi.org/10.1016/j.tourman.2006.05.010>

BALOMENOU, Nika y GARROD, Brian (2014). «Using volunteer-employed photography to inform tourism planning decisions: A study of St David's Peninsula, Wales». Tourism Management, 44, 126-139. $<$ https://doi.org/10.1016/j.tourman.2014.02.015>

BAO, Sandra (dir.) (2015). Argentina y Uruguay: 5 a edición. Barcelona: GeoPlaneta.

BRANDAJS, Fiammetta y SORO, Elsa (2017). Turisme, mobilitat i sostenibilitat. Barcelona: Fundació Universitat Oberta de Catalunya.

BROWN, Richard Harvey (ed.). Postmodern representations: Truth, power and mimesis in the human sciences and public culture. Chicago: University of Illinois Press.

BURFORD, Tim (2011). Uruguay. Barcelona: Alhenamedia.

CAMPRUBí, Raquel y COROMINA, Lluís (2016). «Content analysis in tourism research». Tourism Management Perspectives, 18, 134-140. $<$ https://doi.org/10.1016/j.tmp.2016.03.002>

CATON, Kelle y SANTOS, Carla Almeida (2008). «Closing the hermeneutic circle?: Photographic encounters with the other». Annals of Tourism Research, 35 (1), 7-26. $<$ http://dx.doi.org/10.1016/j.annals.2007.03.014>

CHON, Kye-Sung (1990). «The role of destination image in tourism: A review and discussion». Tourism Review, 45 (2), 2-9. $<$ https://doi.org/10.1108/eb058040>

Coleman, Simon y Crang, Mike (2002). Tourism: Between Place and Performance. Nueva York: Berghan Books.

Crandall, David y Snavely, Noah (2012). «Modeling people and places with internet photo collections». Communication of the ACM, 55 (6), 52-60. <https://doi.org/10.1145/2184319.2184336>

DenZIN, Norman K. (1995). «The poststructural crisis in the social sciences: Learning from James Joyce». En: BROWN, Richard Harvey (ed.). Postmodern representations: Truth, power and mimesis in the human sciences and public culture. Chicago: University of Illinois Press, 134-167.

Dickinson, Janet E.; Ghali, Karen; Cherrett, Thomas; Speed, Chris; Davies, Nigel y NorGATE, Sarah (2014). «Tourism and the smartphone app: Capabilities, emerging practice and scope in the travel domain». Current Issues in Tourism, 17 (1), 84-101. <https://doi.org/10.1080/13683500.2012.718323>

DONA, Ion y POPA, Dan (2013). «Tourism destination mapping through cluster analysis». Scientific Papers Series Management, Economic Engineering in Agriculture and Rural Development, 13 (2), 133-138.

Donaire, José Antonio; Camprubí, Raquel y Galí, Nuria (2014). «Tourist clusters from Flickr travel photography». Tourism Management Perspectives, 11, 26-33. <https://doi.org/10.1016/j.tmp.2014.02.003> 
FAKeye, Paul C. y Crompton, John L. (1991). «Image differences between prospective, first-time, and repeat visitors to the lower Rio Grande Valley». Journal of Travel Research, 30 (2), 10-16. <http://dx.doi.org/10.1177/004728759103000202>

Galí, Núria y DonaIre, José Antonio (2015). "Tourists taking photographs: The long tail in tourists' perceived image of Barcelona». Current Issues in Tourism, 18 (9), 893-902. <http://dx.doi.org/10.1080/13683500.2015.1037255>

Gallarza, Martina G.; Gil Saura, Irene y Calderón García, Haydée (2002). «Destination image: Towards a conceptual framework». Annals of Tourism Research, 29 (1), 56-78. <https://doi.org/10.1016/S0160-7383(01)00031-7>

García-Palomares, Juan Carlos; Gutiérrez, Javier y Mínguez, Carmen (2015). "Identification of tourist hot spots based on social networks: A comparative analysis of European metropolises using photo-sharing services and GPS». Applied Geography, 63, 408-417. <https://doi.org/10.1016/j.apgeog.2015.08.002>

GARROD, Brian (2008). «Exploring place perception: A photo-based analysis». Annals of Tourism Research, 35 (2), 381-401. <https://doi.org/10.1016/j.annals.2007.09.004>

Germann Molz, Jennie y PARIS, Cody Morris (2013). «The social affordances of flashpacking: Exploring the mobility nexus of travel and communication». Mobilities, 10 (2), 173-192. <https://doi.org/10.1080/17450101.2013.848605>

Gordon, Eric y De SouZA E Silva, Adriana (2011). Net Locality: Why Location Matters in a Networked World. Malden: Wiley-Blackwell.

Govers, Robert y Go, Frank M. (2004). «Projected destination image online: Website content analysis of pictures and text». Information Technology and Tourism, 7 (2), 73-89.

Grønflaten, Øyvind (2009). «Predicting Travelers' Choice of Information Sources and Information Channels». Journal of Travel Research, 48 (2), 230-244.

GuMUCHIAN, Hervé (1991). Représentations et aménagement du territoire. París: Anthropos.

HaKlay, M. (2007). "Comparing Map Calculus and Map Algebra in Dynamic GIS». En: Drummond, J.; Billen, R.; Forrest, D. y JoÃo, E. (eds.). Dynamic \& Mobile GIS: Investigating Change in Space and Time. Londres: Taylor \& Francis, 89-104.

Hall, C. Michael y PAGe, Stephen J. (2014.) The geography of tourism and recreation: Environment, place and space. Londres: Routledge.

Hannam, Kevin; Butler, Gareth y PARIS, Cody Morris (2014). «Developments and key issues in tourism mobilities». Annals of Tourism Research, 44, 171-185. <https://doi.org/10.1016/j.annals.2013.09.010>

Hochman, Nadav y MANOVICH, Lev (2013). "Zooming into an Instagram City: Reading the local through social media».First mond@y. Recuperado de <http:// firstmonday.org/article/view/4711/3698> [Fecha de consulta: 27/08/2016].

Hollenstein, Livia y PuRves, Ross (2010). «Exploring place through user-generated content: Using Flickr tags to describe city cores». Journal of Spatial Information Science, 1, 21-48.

HOLLINSHEAD, Keith (2019). "The "worldmaking” prodigy of tourism: The reach and power of tourism in the dynamics of change and transformation». Tourism Analysis, 14 (1), 139-152. <https://doi.org/10.3727/108354209788970162> 
Holsti, Ole R. (1968). «Content Analysis». En: Lindzey, Gardner y Aronson, Elliot (eds.). The handbook of Social Psychology 2. Nueva York: Addison-Wesley, 596-692.

Hughes, Howard L. y Allen, Danielle (2008). "Visitor and non-visitor images of Central and Eastern Europe: A qualitative analysis». International Journal of Tourism Research, 10 (1), 27-40. $<$ https://doi.org/10.1002/jtr.622>

HuNTER, William Cannon (2016). «The social construction of tourism online destination image: A comparative semiotic analysis of the visual representation of Seoul». Tourism Management, 54, 221-229.

<https://doi.org/10.1016/j.tourman.2015.11.012>

- (2012). «Projected destination image: A visual analysis of Seoul». Tourism Geographies, 14 (3), 419-443. <https://doi.org/10.1080/14616688.2011.613407>

Ji, Rongrong; GaO, Yue; ZhOnG, Bineng; YaO, Hongxun y Tian, Qi (2011). «Mining Flickr Landmarks by modelling reconstruction sparsity». ACM Transaction on multimedia computing, Communications and applications, 7 (1), 1-11. <https://doi.org/10.1145/2037676.2037688>

KÁDÁr, Bálint y GEDE, Mátyás (2013). «Where Do Tourists Go?: Visualizing and analysing the Spatial Distribution of Geotagged Photography». Cartographica: The International Journal for Geographic Information and Geovisualization, 48 (2), 78-88. <https://doi.org/10.3138/carto.48.2.1839>

KATSONI, Vicky (2014). "The strategic role of virtual communities and social network sites on tourism destination marketing». e-Journal of Science \& Technology, 5 (9), 107-117. Recuperado de <http://e-jst.teiath.gr/issues/issue_38/Katsoni_38.pdf> [Fecha de consulta: 13/03/2017].

KWAN, Mei-Po (2002). "Feminist visualization: Re-envisioning GIS as a method in feminist geographic research». Annals of the Association of American Geographers, $92(4), 645-661$.

LARSEN, Jonas; URRY, John y AXHAUSEN, Kay W. (2007). «Networks and tourism: Mobile Social Life». Annals of Tourism Research, 34 (1), 244-262. <https://doi.org/10.1016/j.annals.2006.08.002>

LEW, Alan y MCKERCHER, Bob (2006). «Modeling tourist movements: A local destination analysis». Annals of Tourism Research, 33 (2), 403-423. <https://doi.org/10.1016/j.annals.2005.12.002>

Lupei, Theodor; Ciobotaru, Nicu; Badea, Gabriel; Zamfir, Stefan; Matei, Monica; BOBOC, Mădălina; LASLO, Lucian y GYÖRGY, Deák (2017). «Mapping of tourism suitability regarding wetlands». International Journal of Tourism, 2, 1-9.

MaCKaY, Kelly J. y CoUldwell, Christine M. (2004). "Using visitor-employed photography to investigate destination image». Journal of Travel Research, 42 (4), 390-396.

MacKay, Kelly J. y Fesenmaier, Daniel R. (1997). «Pictorial element of destination in image formation». Annals of Tourism Research, 24 (3), 537-565. <https://doi.org/10.1016/S0160-7383(97)00011-X>

Marmolejo, Carlos y Cerdà Troncoso, Jorge (2017). «El comportamiento espacio-temporal de la población como instrumento de análisis de la estructura urbana: El caso de la Barcelona metropolitana». Cuadernos Geográficos, 56 (2), 111-133.

MASSEY, Doreen (2001). "Talking of space-time». Transactions of the institute of British Geographers, 26 (2), 257-261. 
Miah, Shah J.; Vu, Huy Quan; GammaCK, John y McGrath, Michael (2017). «A big data analytics method for tourist behaviour analysis». Information \& Management, 54 (6), 771-785. <https://doi.org/10.1016/j.im.2016.11.011>

MONREAL, Manuel (2012). Uruguay. Madrid: GAESA.

NAVARro, Diego (2015). «Recursos turísticos y atractivos turísticos: Conceptualización, clasificación y valoración». Cuadernos de Turismo, 35, 335-357. <https://doi.org/10.6018/turismo.35.221641>

Pagella, Gabriela (2013). Uruguay: Montevideo, Salto, Punta del Este y más. Madrid: Anaya Touring.

PAN, Bing y LI, Xiang (Robert) (2011). «The long tail of destination image and online marketing». Annals of Tourism Research, 38 (1), 132-152. <https://doi.org/10.1016/j.annals.2010.06.004>

PAÜl I AGUSTí, Daniel (2009). L'oferta cultural en les polítiques de màrqueting de les ciutats. Lleida: Universitat de Lleida.

- (2014). «Differences in the location of urban museums and their impact on urban areas». International Journal of Cultural Policy, 20 (4), 471-495. <http://dx.doi.org/10.1080/10286632.2013.850498>

Pritchard, Annette y MorgAn, Nigel (1995). "Evaluating vacation destination brochure images: The case of local authorities in Wales». Journal of Vacation Marketing, 2 (1), 23-38.

Raun, Janika; AHAS, Rein y TIRU, Margus (2016). «Measuring tourism destinations using mobile tracking data». Tourism Management, 57, 202-212. <https://doi.org/10.1016/j.tourman.2016.06.006>

RELPH, Edward (1976). Place and placeness. Londres: Pion.

Ryan, Chris y Cave, Jenny (2005). «Structuring destination image: A qualitative approach». Journal of Travel Research, 44 (2), 143-150.

Schwartz, Raz y Halegoua, Germaine R. (2015). "The spatial self: Locationbased identity performance on social media». New Media \& Society, 17 (10), 1643-1660.

Seabra, Claudia; Abrantes, Jose Luis y Lages, Luis Filipe (2007). «The impact of using non-media information sources on the future use of mass media information sources: The mediating role of expectations fulfillment». Tourism Management, 28 (6), 1541-1554.

<https://doi.org/10.1016/j.tourman.2007.02.008>

Serrano i Miracle, Damià e Imbert-Bouchard Ribera, Daniel (2009). "Anàlisi de mercat: La Catalunya que es ven a les principals guies turístiques» En: López Palomeque, Francesc (dir.). Atles del turisme a Catalunya. Barcelona: Generalitat de Catalunya, 389-405.

Shoval, Noam e IsAaCSON, Michael (2007). "Tracking tourists in the digital age». Annals of Tourism Research, 34 (1), 141-159. <https://doi.org/10.1016/j.annals.2006.07.007>

Shoval, Noam y RaveH, Adi (2004). "Categorization of tourist attractions and the modelling of tourist cities: Based on the co-plot method of multivariate analysis». Tourism Management, 25 (6), 741-750. <https://doi.org/10.1016/j.tourman.2003.09.005>

Shoval, Noam; SCHVImer, Yonatan y TAMIR, Maya (2018). «Tracking technologies and urban analysis: Adding the emotional dimension». Cities, 72, 34-42. <https://doi.org/10.1016/j.cities.2017.08.005> 
Smith, Andrew (2005). "Conceptualizing city image change: The "re-imaging" of Barcelona». Tourism Geographies, 7 (4), 398-423. <https://doi.org/10.1080/14616680500291188>

Sosa, Víctor (2016). Anuario 2016 Estadisticas de Turismo. Montevideo: Ministerio de Turismo.

STASZAK, Jean-François (2014). "Géographie et cinéma: Modes d'emploi». Annales de Géographie, 1-2, 695-696. <https://doi.org/10.3917/ag.695.0595>

STEPCHENKOVA, Svetlana y ZHAN, Fangzi (2013). «Visual destination images of Peru: Comparative content analysis of DMO and user-generated photography». Tourism Management, 36 (6), 590-601. <https://doi.org/10.1016/j.tourman.2012.08.006>

STEWART, Kathleen (2005). «Cultural poesis: The generativity of emergent things». En: Denzin, Norman K. y Lincoln, Yvonna S. (eds.). The Sage handbook of qualitative research. Londres: Sage, 1027-1042.

STYLianOU-LAmbeR, Theopisti (2012). "Tourists with Cameras: Reproducing or Producing?». Annals of Tourism Research, 39 (4), 1817-1838. <https://doi.org/10.1016/j.annals.2012.05.004>

TAsci, Asli D.A. y GarTner, William C. (2007). «Destination image and its functional relationships». Journal of Travel Research, 45 (4), 413-425.

Terrell, George R. y SCOTT, David W. (1992). «Variable Kernel density estimation». The Annals of Statistics, 20 (3), 1236-1265.

WOLCOTT, Harry F. (1995). "Making a study "more ethnographic"». En: VAN MAANEN, John (ed.). Representation in ethnography. Londres: Sage, 79-111.

YAN, Grace y SANTOS, Carla Almeida (2009). "CHINA, FOREVER": Tourism discourse and self- orientalism». Annals of Tourism Research, 36 (2), 295-315. <https://doi.org/10.1016/j.annals.2009.01.003>

ZHOU, Lingxu (2014). «Online rural destination images: Tourism and rurality». Journal of Destination Marketing \& Management, 3 (4), 227-240. <https://doi.org/10.1016/j.jdmm.2014.03.002> 